\title{
EDITORIAL
}

\section{DIRETRIZES DO COPE PARA O TRABALHO DE EDITORES DE PERIÓdICOS CIENTÍFICOS}

Durante a $2^{\text {a }}$ Conferência Mundial sobre Integridade da Pesquisa de Singapura, 22 a 24 de julho de 2010, o COPE ${ }^{1}$ - Committee on Publication Ethics ajudou a desenvolver duas declarações que estabelecem padrões internacionais para publicação de pesquisa responsável para autores e editores.

Os documentos foram publicados como parte dos procedimentos da Conferência sob uma licença Creative Commons. O COPE encoraja editores a republicar as declarações em suas próprias revistas e a fazer referência ou a incorporá-las nas suas políticas e instruções editoriais para os autores.

Neste Vol. 20, n.1, 2019 da EJJL publicaremos a tradução da versão original em inglês dos padrões recomendados para EDITORES. No Vol. 19, n.1, 2018 publicamos a tradução dos padrões recomendados para AUTORES.

A EJJL vai incorporar estas orientações na sua política editorial.

Boa leitura.

Carlos Luiz Strapazzon

Editor-chefe

Jun. 2019

1 O COPE foi criado em 1997 por um pequeno grupo de editores de revistas no Reino Unido, mas atualmente tem mais de 12000 membros em todo o mundo de todas as áreas do conhecimento científico. A adesão está aberta a editores de revistas acadêmicas e outros interessados em ética de publicação. O COPE fornece conselhos a casas editoriais e a editores sobre todos os aspectos da ética da publicação e, em particular, sobre como lidar com casos de conduta indevida na pesquisa e em publicações. Não investiga casos individuais. O COPE também financia pesquisa, organiza seminários anuais a nível mundial e criou uma ferramenta de auditoria para que os membros avaliem suas políticas e práticas contra os princípios de publicação do COPE, descritos nas Práticas básicas. Mais informações, ver: https://publicationethics.org/about 


\title{
PUBLICAÇÃO RESPONSÁVEL DA PESQUISA: \\ PADRÕES INTERNACIONAIS PARA EDITORES ${ }^{2}$
}

\section{Declaração de posição desenvolvida na $2^{a}$ Conferência Mundial sobre Integridade da Pesquisa, Singapura, 22 a 24 de julho de 2010}

\author{
Elizabeth Wager \& Sabine Kleinert ${ }^{3}$
}

\section{Para citar a versão original em inglês:}

Kleiner, S., \& Wager, E. (2011). Responsible research publication: international standards for editors. A position statement developed at the 2nd World Conference on Research Integrity, Singapore, July 22-24, 2010. Chapter 51. In T. Mayer \& N. Steneck (Eds.), Promoting Research Integrity in a Global Environment. Imperial College Press/World Scientific Publishing, Singapore (pp 317-28). ISBN 978-981-4340-97-7

\section{Sumário}

- Editores devem assumir a responsabilidade por tudo que publicam;

- Editores devem tomar decisões justas, imparciais, independentes de considerações comerciais e garantir um processo justo e adequado de revisão por pares;

- Editores devem adotar políticas editoriais que incentivem a máxima transparência, relatórios completos de pesquisa e honestos;

- Editores devem proteger a integridade do registro publicado, emitir correções e retratações quando necessário, e investigar a conduta suspeita, ou alegada, de má conduta em pesquisa e na publicação;

- Editores devem investigar revisores e má conduta editorial;

- Editores devem avaliar criticamente a conduta ética de estudos com seres humanos e também com animais;

- Revisores e autores devem ser informados sobre o que se espera deles;

- Editores devem ter políticas adequadas para lidar com conflitos de interesse editorial.

\footnotetext{
2 Disponível em: https://publicationethics.org/node/11184. A permissão para republicação não é necessária. A autorização das autoras para publicar a versão em língua portuguesa foi concedida em 18.04.2018. Esta tradução foi finalizada em 26.Jun.2019 por Carlos Luiz Strapazzon, Editor-Chefe da EJJL, Prof. de Direito Constitucional do Programa de Pós-Graduação em Direito da UNOESC e do Programa de Pós-Graduação da Escola de Direito da Universidade Positivo-PR, Brasil. Email: strapazzon.carlos.luiz@gmail.com; ACADEMIA: https://cstrapazzon.academia.edu; BEPRESS: works.bepress. com/carlos_strapazzon/

3 Contato: liz@sideview.demon.co.uk, sabine.kleinert@lancet.com
} 


\section{Introdução}

Como guardiões e administradores dos registros de pesquisa, editores de periódicos científicos devem encorajar autores a se esforçarem para aderir aos mais elevados padrões de ética na publicação. Além disso, editores estão em uma posição única para promover, indiretamente, a conduta responsável durante a pesquisa por meio de suas políticas e processos. Para alcançar o efeito máximo na comunidade de pesquisa, idealmente todos os editores devem aderir a padrões universais de boas práticas. Embora existam diferenças importantes entre campos de saber e nem todas as boas práticas específicas sejam relevantes para todas as comunidades de pesquisa, existem importantes políticas, processos e princípios editoriais comuns que editores devem seguir para garantir a integridade do registro da pesquisa.

As diretrizes deste documento são um ponto de partida e visam os editores de periódicos científicos. Embora livros e monografias também sejam registros de pesquisas importantes e relevantes em muitos campos, as diretrizes para editores de livros estão além do escopo destas recomendações. Espera-se que no devido tempo tais diretrizes possam ser acrescidas a este documento.

Editores de periódicos científicos devem considerar-se parte de uma comunidade editorial profissional mais ampla, devem manter-se ao par de políticas e desenvolvimentos relevantes e garantir que sua equipe editorial seja treinada e bem informada sobre questões relevantes.

Ser um bom editor requer muito mais princípios do que os abordados aqui. Os princípios, políticas e processos aqui sugeridos visam, particularmente, promover a integridade da pesquisa e das publicações.

\section{PRINCÍPIOS EDITORIAIS}

\section{Prestação de contas e responsabilidade pelo conteúdo do periódico}

Editores devem se responsabilizar por tudo que publicam e devem ter procedimentos e políticas para garantir a qualidade do material que publicam e manter a integridade do registro publicado (ver parágrafos 4-8).

\section{Independência e integridade editorial}

Uma parte importante da responsabilidade de tomar decisões justas e imparciais é a manutenção dos princípios de independência e de integridade editorial. 


\subsection{Separar a tomada de decisão de considerações comerciais}

Editores devem tomar decisões com base no mérito acadêmico e assumir total responsabilidade por suas decisões. Os processos em vigor devem estar delineados para separar as atividades comerciais de um periódico de seus processos editoriais e decisões meritocráticas. Editores devem ter um interesse ativo nas políticas de preços das editoras e buscar acessibilidade ampla e acessível do material que publicam.

Os suplementos patrocinados devem passar pelo mesmo rigoroso controle de qualidade e revisão por pares de qualquer outro conteúdo do periódico. As decisões sobre esse material devem ser tomadas da mesma forma que qualquer outro conteúdo de revista. Patrocínio e o papel do patrocinador devem ser explicitamente declarados aos leitores.

Anúncios precisam ser verificados para que sigam as diretrizes do periódico, e para que sejam claramente distinguíveis de outros conteúdos e para que não se vinculem, forma alguma, ao conteúdo acadêmico.

\subsection{Relacionamento de editores com as Editoras ou com os proprietários do periódico}

Idealmente, editores devem ter um termo escrito que estabelece as condições de sua nomeação com a Editora ou com o proprietário do periódico. O princípio da independência editorial deve ser claramente definido nesse termo. Editoras e proprietários de periódicos não devem influenciar as decisões sobre o conteúdo das publicações por causa de interesses comerciais ou políticos. As Editoras não devem dispensar editores por causa de algum conteúdo publicado pelo periódico, a menos que tenha havido grosseira má conduta editorial ou se uma investigação independente concluir que a decisão de publicar conflitava com a missão acadêmica do periódico.

\subsection{Classificações, rankings e tomada de decisão}

Editores não devem tentar influenciar a classificação de seu periódico pelo aumento artificial de resultados de qualquer indicador. Por exemplo, é inadequado exigir a inclusão de referências em artigos da revista, exceto por motivos genuinamente acadêmicos. Em geral, editores devem garantir que os artigos sejam revisados em bases puramente acadêmicas e que os autores não sejam pressionados a citar publicações específicas por razões não-acadêmicas. 


\section{Confidencialidade editorial}

\subsection{Material dos autores}

Se um periódico adota um modelo segundo o qual os revisores são escolhidos pelos editores (ao invés de postar uma versão preliminar de artigos para comentários abertos), os editores devem proteger a confidencialidade do material dos autores e lembrar os revisores de fazê-lo também. Como regra geral, editores não devem compartilhar com editores de outras revistas os artigos submetidos, a menos que haja acordo com os autores ou em casos de suposta má conduta (veja abaixo). Editores geralmente não têm obrigação de fornecer material a advogados para casos judiciais. Os editores não devem dar qualquer indicação sobre o status de um artigo no periódico para alguém que não seja o autor. Os sistemas de envios baseados na Web devem ser configurados de maneira a impedir o acesso não autorizado.

No caso de uma investigação de conduta indevida, pode ser necessário divulgar material a terceiros (por exemplo, um comitê de investigação institucional ou outros editores).

\subsection{Revisores}

A identidade dos revisores deve ser protegida pelos Editores, a menos que operem num sistema aberto de revisão por pares. No entanto, se revisores desejarem divulgar seus nomes, isso deve ser permitido.

Se houver alguma má conduta alegada, ou suspeita, em relação a algum revisor, pode ser necessário divulgar seu nome a terceiros.

\section{POLÍTICAS EDITORIAIS GERAIS}

\section{Incentivar a máxima transparência e relatórios completos e honestos}

Para avançar o conhecimento acadêmico, é importante entender por que um trabalho específico de pesquisa foi realizado, como foi planejado e conduzido e por quem e o que ele acrescenta ao conhecimento atual. Para alcançar esse entendimento, a máxima transparência e a comunicação completa e honesta são cruciais. 


\subsection{Autoria e responsabilidade}

Os periódicos devem ter uma política clara de autoria que siga os padrões relevantes da área. Em suas informações, devem oferecer orientação para autores sobre o que se espera de um autor e, se houver diferentes regras de autoria dentro de uma área, o periódico devem explicitar quais adota.

Para pesquisas multidisciplinares e colaborativas, deve ficar evidente para os leitores quem fez o que e quem assume a responsabilidade pela conduta e validade de cada aspecto da pesquisa. Cada parte do trabalho deve ter, pelo menos, um autor que assuma a responsabilidade pela sua validade. Por exemplo, contribuições e responsabilidades individuais podem ser declaradas em uma seção à parte. Espera-se que todos os autores tenham contribuído significativamente para o artigo e estejam familiarizados com todo o seu conteúdo e, idealmente, isso deve ser manifesto em uma declaração de autoria enviada ao periódico.

Quando houver mudanças indiscutíveis na autoria por razões bem justificadas, os editores devem exigir que todos os autores (incluindo aqueles cujos nomes estão sendo removidos de uma lista de autores) concordem com isso, e por escrito. Disputas de autoria (ou seja, discordâncias sobre quem deve ou não ser autor antes ou depois da publicação) não podem ser julgadas pelos editores e devem ser resolvidas no nível institucional, ou por outros órgãos independentes apropriados para artigos publicados e não publicados. Editores devem agir sobre os resultados, por exemplo, corrigindo a autoria em artigos publicados.

Os periódicos devem ter uma política declarada sobre como os artigos submetidos pelos editores, ou membros do conselho editorial, são tratados (ver parágrafo sobre conflitos de interesse editorial: 8.2).

\subsection{Conflitos de interesse e papel da fonte de financiamento}

Editores devem ter políticas que exijam que todos os autores declarem conflitos de interesses financeiros e não financeiros relevantes e publicar, pelo menos, aqueles que possam influenciar a percepção do leitor de um artigo, juntamente com o artigo. A fonte de financiamento da pesquisa deve ser declarada e publicada, e deve ser declarado e publicado também o papel da fonte de financiamento na concepção, condução, análise e relato da pesquisa.

Editores devem deixar claro em suas informações para autores se em certas seções da revista (por exemplo, comentários encomendados ou artigos de revisão) certos conflitos de interesse impedem certos perfis de autoria. 


\subsection{Relatórios completos e honestos e aderência às diretrizes de relatórios}

Entre as responsabilidades mais importantes dos editores destaca-se a de manter um alto padrão na literatura acadêmica. Embora os padrões sejam diferentes entre os periódicos, editores devem trabalhar para garantir que todos os artigos publicados ofereçam uma nova e substancial contribuição para a sua área. Editores devem desencorajar as chamadas 'publicações salaminho' (ou seja, publicação fracionada, restrita a uma unidade mínima de uma pesquisa abrangente), evitar publicação duplicada ou redundante, a menos que seja totalmente declarada e aceitável para todos (por exemplo, publicação em um idioma diferente com referência cruzada) e encorajar autores a colocar seu trabalho no contexto do trabalho anterior (por exemplo, afirmar por que esse trabalho foi necessário/feito, o que o novo trabalho acrescenta ou por que uma replicação de trabalhos anteriores era necessária e o que os leitores deveriam saber dele).

Os periódicos devem adotar políticas que estimulem o relato integral e honesto da pesquisa, por exemplo, exigindo que autores trabalhem em áreas nas quais seja padrão enviar protocolos ou planos de estudo e, onde existirem, que forneçam evidências de adesão a tais diretrizes relevantes para a versão final dos relatórios de pesquisa. Embora planejada para melhorar o relato, a aderência a diretrizes de relatórios também facilita o julgamento da conduta real da pesquisa, tanto para editores, quanto para revisores e leitores.

Arquivos de imagens digitais, figuras e tabelas devem seguir padrões apropriados da área. Imagens não devem ser inadequadamente alteradas de modo a desviar seu propósito.

Usando software anti-plágio, ou de manipulação de imagens, editores também podem considerar a triagem de plágio, publicação duplicada ou redundante. Se for detectado plágio ou manipulação fraudulenta de imagens, isso deve ser reportado aos autores e a instituições relevantes (ver parágrafo sobre como lidar com má conduta: 5.2).

\section{Responder a críticas e preocupações}

A reação e a resposta à pesquisa publicada por outros pesquisadores é uma parte importante do debate acadêmico na maioria das áreas e deve ser encorajada por editores. Em algumas áreas, os periódicos podem facilitar o debate publicando as respostas de leitores. Críticas podem ser parte de um debate acadêmico geral, mas também podem destacar transgressões de pesquisa ou integridade de publicação.

\subsection{Garantir a integridade do registro publicado e correções}

Quando erros genuínos em trabalhos publicados são apontados por leitores, autores ou editores, que não tornam o trabalho inválido, uma correção (ou errata) deve ser publicada o mais 
rápido possível. A versão on-line do artigo pode ser corrigida com uma data de correção e um link para a errata impressa. Se o erro compromete todo o trabalho ou parte substancial, o artigo deve ser recolhido com uma explicação sobre o motivo da retratação (ou seja, erro honesto).

\subsection{Garantir a integridade do registro publicado e suspeita de má conduta de pesquisa ou publicação}

Se preocupações sérias forem levantadas por leitores, revisores ou outros sobre a conduta, validade ou relato do trabalho acadêmico, os editores devem inicialmente contatar os autores (idealmente todos os autores) e permitir que eles respondam às preocupações. Se a resposta for insatisfatória, os editores devem levar isso ao nível institucional (veja abaixo). Em casos raros, principalmente no campo biomédico, quando as preocupações são muito sérias e o trabalho publicado provavelmente influencia a prática clínica ou a saúde pública, os editores devem considerar a possibilidade de informar os leitores sobre tais preocupações, por exemplo, emitindo uma 'expressão de preocupação', enquanto a análise do caso prossegue.

Quando uma análise é concluída, ações apropriadas devem ser tomadas pelos editores com um comentário que explique as descobertas e conclusões. Editores também devem responder a descobertas de organizações nacionais de integridade de pesquisa que apontem conduta imprópria relacionada a um artigo publicado em seu periódico. Os próprios editores podem decidir retirar um trabalho se estiverem convencidos de que houve má conduta grave, mesmo que uma investigação de uma instituição ou órgão nacional não o recomende.

Os editores devem responder a todas as alegações ou suspeitas de má conduta de pesquisa ou publicação levantadas por leitores, revisores ou outros editores. Em geral, os editores são os primeiros destinatários de informações sobre essas preocupações e devem agir, mesmo no caso de um artigo que não tenha sido aceito ou que já tenha sido rejeitado.

Além das responsabilidades específicas pelas publicações em seus periódicos, os editores também têm responsabilidade coletiva pela idoneidade dos registros das pesquisas em outros meios e, sempre que possível, devem agir quando tomarem conhecimento de alguma possível má conduta. Casos de possível plágio ou de publicação duplicada/redundante podem ser avaliados pelos próprios editores. No entanto, na maioria dos outros casos, editores devem solicitar uma investigação pela instituição ou por outros órgãos apropriados. Antes, porém, devem buscar uma explicação diretamente dos autores; após isso, e se a explicação recebida for insatisfatória, devem dirigir-se a outros órgãos.

Os documentos recolhidos devem ser retidos on-line e devem ser destacados como uma retratação em todas as versões on-line, incluindo o PDF, para benefício dos futuros leitores. 
Para obter mais orientações sobre alegações específicas e ações sugeridas, como retratações, consulte os fluxogramas e diretrizes de retratação da COPE:

http://publicationethics.org/flowcharts;

http://publicationethics.org/files/u661/Retractions_COPE_gline_final_3_Sept_09_2_.pdf.

\subsection{Incentivar o debate acadêmico}

Todos os periódicos devem considerar o melhor meio pelo qual os leitores possam discutir artigos e aprimorar o debate (em muitas áreas isso é feito em uma seção de correspondência impressa ou on-line). Os autores podem contribuir para o debate, sendo permitido responder a comentários e críticas sempre que isso seja relevante. Esse debate acadêmico sobre o trabalho publicado deve acontecer em tempo hábil. Editores devem distinguir claramente as críticas às limitações de um estudo e as críticas que levantam a possibilidade de desvios de pesquisa. Quaisquer críticas que levantem a possibilidade de má conduta não devem ser apenas publicadas, mas devem ser investigadas, mesmo que sejam recebidas ao longo do tempo após a publicação.

\section{POLÍTICAS EDITORIAIS RELEVANTES PARA PERIÓDICOS QUE PUBLICAM PESQUISAS SOBRE SERES HUMANOS OU ANIMAIS}

\section{Avaliar criticamente e exigir um alto padrão de conduta ética de pesquisa}

Especialmente na pesquisa biomédica, mas também nas ciências sociais e humanas, a conduta ética durante a pesquisa é primordial para proteger seres humanos e animais. A supervisão ética, os procedimentos de consentimento apropriados e a adesão às leis relevantes devem ser obrigatórias para autores. Editores precisam estar atentos às preocupações específicas desse tipo de pesquisa.

\subsection{Aprovação ética e conduta ética}

Para a pesquisa médica com seres humanos, em geral, editores devem requerer a aprovação do artigo por um comitê de ética (ou conselho de revisão institucional) e a garantia de que a pesquisa foi conduzida de acordo com a Declaração de Helsinque. Além disso, devem estar atentos às questões sensíveis à conduta ética da pesquisa. Isso pode significar a necessidade de um artigo ser enviado para revisores com especialização específica na área, para o comitê de ética do periódico, se houver, ou que editores precisam de mais garantias (evidências) de parte dos autores ou de suas instituições.

Os artigos podem ser rejeitados por motivos éticos, mesmo que a pesquisa tenha sido aprovada pelo comitê de ética. 


\subsection{Consentimento (para participar da pesquisa)}

Se a pesquisa for feita com seres humanos, editores devem garantir que seja incluída, junto com o artigo, uma declaração sobre o procedimento de consentimento. $\mathrm{Na}$ maioria dos casos o consentimento informado por escrito é a exigência necessária. Se houver alguma preocupação com o procedimento de consentimento, se a pesquisa for feita com grupos vulneráveis ou se houver dúvidas sobre a conduta ética, os editores devem pedir para ver o formulário de consentimento e pedir informações mais precisas aos autores sobre como foi obtido o consentimento.

\subsection{Consentimento (para publicação)}

Para todos os relatos de casos, pequenas séries de casos e imagens de pessoas, os editores devem exigir que os autores tenham o consentimento explícito para publicação (que é diferente do consentimento para participar da pesquisa). O consentimento deve informar aos participantes em qual revista o trabalho será publicado, deixar claro que, apesar de todos os esforços serem feitos para remover identificadores desnecessários, o anonimato completo não é possível, e declarar também que a pessoa mencionada no estudo viu e concordou com a versão final do trabalho a ser submetido para publicação.

O formulário de consentimento assinado deve ser mantido com o arquivo do paciente em vez de ser enviado para o periódico (para maximizar a proteção e a confidencialidade dos dados, consulte o parágrafo 6.4). Pode haver exceções em que não é possível obter consentimento, por exemplo, quando a pessoa morreu. Em tais casos, uma cuidadosa consideração sobre possíveis danos é necessária e, afora as razões de cortesia, devem ser feitos esforços para obter consentimento dos familiares da pessoa estudada. Em casos muito raros, uma importante mensagem da área da saúde pública pode justificar a publicação sem consentimento, desde que não tenha sido possível obtê-lo, apesar de todos os esforços, e também porque, afinal, há razões para sustentar que o benefício da publicação supera um possível dano.

\subsection{Proteção de dados e confidencialidade}

Os editores devem avaliar criticamente qualquer potencial violação de proteção de dados e confidencialidade da pessoa estudada no artigo. Isso inclui a exigência de consentimento informado para a pesquisa apresentada, o consentimento para publicação, quando aplicável (ver parágrafo 6.3), e a adoção de políticas editoriais em conformidade com as diretrizes sobre confidencialidade da pessoa estudada. 


\subsection{Aderência às leis relevantes e às diretrizes de melhores práticas para conduta ética}

Editores devem exigir que autores cumpram as leis nacionais e internacionais relevantes e as diretrizes de melhores práticas, quando aplicáveis, por exemplo, ao realizar pesquisas com animais. Editores devem incentivar o registro de ensaios clínicos.

\section{PROCESSOS EDITORIAIS}

\section{Assegurar um processo justo e apropriado de revisão pelos pares}

Uma das responsabilidades mais importantes de editores é organizar e usar a revisão por pares de maneira justa e inteligente. Editores devem explicar seus processos de revisão por pares nas informações para autores e também indicar quais partes ou seções da revista são revisadas por pares.

\subsection{Decisão sobre revisar por pares, ou não}

Editores podem rejeitar um artigo sem revisão por pares quando for considerado inadequado para os leitores da revista ou de baixa qualidade. Essa decisão deve ser tomada de maneira justa e imparcial. Os critérios usados para tomar essa decisão devem ser explicitados. A decisão de não enviar um artigo para revisão por pares deve basear-se apenas no conteúdo acadêmico do artigo e não deve ser influenciada pela natureza dos autores ou da instituição anfitriã.

\subsection{Interação com revisores}

Editores devem usar revisores apropriados para trabalhos que são considerados aptos para publicação, selecionar pessoas com conhecimento suficiente e evitar aqueles com conflitos de interesse. Editores devem garantir que as revisões sejam recebidas em tempo hábil.

Os revisores devem ser informados sobre o que se espera deles e devem ser informados sobre quaisquer mudanças nas políticas editoriais. Em particular, revisores devem ser solicitados a avaliar questões de ética em pesquisa e publicação (ou seja, se eles acham que a pesquisa foi feita e relatada eticamente, ou se eles têm alguma suspeita de plágio, fabricação, falsificação ou publicação redundante). Editores devem ter uma política para solicitar uma declaração formal de conflito de interesses dos revisores e pedir aos revisores para informá-los sobre qualquer conflito de interesse na primeira oportunidade, para que possam decidir se uma revisão imparcial é possível. Certos conflitos de interesse podem desqualificar um revisor. Editores também devem enfatizar a confidencialidade do material para os revisores e devem exigir que os revisores informem quando pedem ajuda a um colega para uma revisão ou se forem mentores de um colega mais jovem na condução de uma 
revisão por pares. Idealmente, os editores devem ter um mecanismo para monitorar a qualidade e a oportunidade da revisão por pares e fornecer feedback a revisores.

\subsection{Má conduta do revisor}

Editores devem levar a sério a má conduta de revisores e investigar qualquer alegação de quebra de confidencialidade, não declaração de conflitos de interesses (financeiros ou não financeiros), uso inadequado de material confidencial ou atraso na revisão por pares para obter vantagem competitiva.

Alegações de má conduta sérias de um revisor, como o plágio, devem ser levadas ao nível institucional.

Quanto a isso, ver:

http://publicationethics.org/files/u2/07_Reviewer_misconduct.pdf.

\subsection{Interação com os autores}

Editores devem deixar claro para autores qual é a função de um revisor de pares, pois isso pode variar de periódico para periódico. Alguns editores consideram os revisores como conselheiros e podem não necessariamente seguir (ou mesmo pedir) recomendações dos revisores sobre aceitação ou rejeição. A correspondência dos editores é geralmente com o autor, que deve garantir a participação de coautores em todas as etapas. A comunicação com todos os autores na primeira submissão e no estágio de aceitação final pode ser útil para garantir que todos os autores estejam cientes da submissão e tenham aprovado a publicação. Normalmente, os editores devem transmitir os comentários de todos os revisores na íntegra. No entanto, em casos excepcionais, pode ser necessário excluir partes de uma revisão, se, por exemplo, ela contiver comentários difamatórios ou ofensivos. É importante, no entanto, que tal critério editorial não seja usado de forma inadequada para suprimir comentários inconvenientes.

Sempre deve haver boas razões, que serão claramente comunicadas aos autores, se revisores adicionais forem procurados em um estágio final do processo de revisão. A decisão editorial final e as razões para isso devem ser claramente comunicadas aos autores e revisores. Se um artigo for rejeitado, é recomendável que os editores tenham algum procedimento de pedido de reconsideração. Os editores, no entanto, não são obrigados a reverter sua decisão. 


\section{Tomada de decisão editorial}

Editores estão em uma posição poderosa ao tomar decisões sobre publicações, o que torna muito importante que esse processo seja o mais justo e imparcial possível, e esteja de acordo com a visão acadêmica do periódico em particular.

\subsection{Processos editoriais e de periódicos}

Todos os processos editoriais devem ser claros nas informações para autores. Em particular, deve-se declarar o que se espera de autores, quais tipos de artigos são publicados e como os artigos são tratados pelo periódico. Todos os editores devem estar totalmente familiarizados com as políticas, visão e escopo do periódico. A responsabilidade final por todas as decisões é do editor-chefe.

\subsection{Conflitos editoriais de interesse}

Editores não devem estar envolvidos em decisões sobre documentos nos quais tenham conflito de interesses, por exemplo, se trabalham ou trabalharam na mesma instituição e colaboraram com os autores, se possuem ações em uma determinada empresa, ou se eles têm um relacionamento pessoal com autores. Os periódicos devem ter um processo definido para lidar com trabalhos assim.

Os periódicos também devem ter um processo para lidar com artigos submetidos por editores ou membros do conselho editorial para garantir o manuseio imparcial e independente de tais trabalhos. Esse processo deve ser declarado nas informações para autores. Conflitos de interesses editoriais devem ser declarados, e, idealmente publicados. 
